\title{
EVIDENCE OF INTRADAY MULTIFRACTALITY IN BRIC STOCK MARKETS: AN ECONOPHYSICS APPROACH
}

\author{
Rui Dias ${ }^{1}$ \\ Paula Heliodoro ${ }^{2}$ \\ Paulo Alexandre ${ }^{3}$ \\ Maria Manuel $^{4}$
}

DOI: https://doi.org/10.31410/ITEMA.S.P.2020.57

\begin{abstract}
The pandemic outbreak (Covid-19) has affected the global economy, and the impact on financial markets seems inevitable. In view of these events, this essay intends to analyse the efficiency, in its weak form, in the BRIC markets, namely the stock indexes of Brazil (BRAZIL IBOVESPA), China (Shanghai Stock Exchange), India (S\&P BSE SENSEX), Russia (MOEX Russia). The data are intraday (1 hour), from May 2019 to May 2020; to obtain more robust results, we divided the sample into time scales up to 5 days (Period I), and above 10 days (Period II), in a complementary way, and we use the opening and closing prices to estimate the adjustment time of each market. The results indicate that the BRIC markets have significant persistence (over 10 days), which may jeopardize market efficiency, in its weak form. On the other hand, the low initial correlation in certain stock indexes may create some arbitrage opportunities. However, our study did not analyse anomalous returns in these financial markets. These conclusions also open space for market regulators to take measures to ensure better information between these markets and international ones.
\end{abstract}

Keywords: COVID-19, BRIC, Long memories, Arbitration.

\section{INTRODUCTION}

$\mathrm{O}$ n December 31, 2019, the World Health Organization (WHO) in China received a report of 29 pneumonia cases of unknown ethology in the city of Wuhan, in central Hubei province, China. The virus was quickly identified as a new beta-coronavirus and the genetic sequence was shared on January 12, 2020. The infection is officially called Covid-19. The news of this outbreak caused many public health officials to feel spontaneous by recalling the events of the outbreak of severe acute respiratory syndrome (SARS) that emerged in China in November 2002 (Jimmy Whitworth, 2020).

The outbreak of COVID-19 has caused global concern. On 30 January, WHO declared it a global health emergency. The easy spread of this virus has caused uncertainty in the global population. This epidemic has also changed people's lifestyles, millions of people have been placed in isolation in order to reduce the transmission of the virus, companies have closed to control the spread of the virus, causing income losses and leading to significant levels of

Escola Superior de Ciências Empresariais - Instituto Politécnico de Setúbal, Portugal \& CEFAGE, Universidade de Évora, Portugal

Escola Superior de Ciências Empresarias - Instituto Politécnico de Setúbal, Portugal

Escola Superior de Ciências Empresarias - Instituto Politécnico de Setúbal, Portugal

Escola Superior de Ciências Empresarias - Instituto Politécnico de Setúbal, Portugal 
unemployment. In general, economic activities have been disrupted and stock exchanges have dropped sharply (Saadat, Rawtani, and Hussain, 2020).

This essay intends to examine the efficiency, in its weak form, in the BRIC markets, namely the stock indexes of Brazil (BRAZIL IBOVESPA), China (Shanghai Stock Exchange), India (S\&P BSE SENSEX), Russia (MOEX Russia). The data are intraday (1 hour), from May 2019 to May 2020; to obtain more robust results, we divided the sample into time scales up to 5 days (Period I), and above 10 days (Period II); also, we use the opening and closing prices to estimate the adjustment time for each market. The results indicate that the BRIC markets have significant persistence (over 10 days), which may jeopardize market efficiency, in its weak form. On the other hand, the low initial correlation in certain stock indexes may create some arbitrage opportunities.

This investigation adds two main contributions to the literature. The first contribution refers to the study of informational efficiency in the BRIC markets, with intraday data (1 hour), in the context of the global pandemic (Covid-19). As far as we know, this is the first study to analyse these financial markets in isolation. However, there are recent studies that have investigated the impact of the 2020 global pandemic on financial markets, namely the studies by authors Ma, Rogers, and Zhou (2020), Liu, Manzoor, Wang, Zhang, and Manzoor (2020). However, the research questions, the markets analysed, and the approach was essentially different from the one followed in this essay.

The second contribution is of an econophysical nature since two econophysical methods are compared that corroborate each other. In particular, the Detrended Fluctuation Analysis (DFA) methodology, which will measure the presence or absence of long memories in these stock indexes and test whether these markets are efficient, in their weak form. We will use the Detrended Cross-Correlation Analysis (DCCA) to measure cross-correlations without trend between the opening and closing prices of each market, to assess whether the markets adjust efficiently during trading.

In terms of structure, this essay is organized into 5 sections. Section 2 presents an analysis of the State of the Art regarding articles on the hypothesis of an efficient market in international financial markets. Section 3 describes the methodology. Section 4 contains the data and results. Section 5 concludes.

\section{LITERATURE REVISION}

An efficient market is a market in which the prices of securities traded reflect all available information. The Efficient Market Hypothesis (HME), in its weak form, understands that the previous movement of stock prices is incorporated in the current prices of securities; therefore, it can be used to predict the current price or profitability. (Agustin, 2019)

The topic about the efficient market hypothesis (EMH) has motivated other studies to analyse the implications for the market efficiency hypothesis, according to which the current price of the assets reflects all the information available, at a given moment, and the adjusted price quickly, as new and unforeseen information hits the market (Fama and French, 1988).

Nisar and Hanif (2012), Mehla and Goyal (2013), El Khamlichi et al. (2014), Mobarek and Fiorante (2014) tested the random walk hypothesis in several stock markets. Nisar and Hanif (2012) analysed the stock markets of India, Pakistan, Bangladesh and Sri Lanka, and show (in) 
market efficiency, in its weak form. Mehla and Goyal (2013) suggest that the Indian market does not support the random walk hypothesis, showing signs of inefficiency. El Khamlichi et al. (2014) show that Islamic indices have the same level of (in) efficiency as benchmarks, but the MSCI and FTSE indices are less inefficient. Mobarek and Fiorante (2014) show that the stock markets of Brazil, Russia, India and China (BRIC) can be considered efficient, in their weak form, in the analysed period.

Krsikapa-Rasajski and Rankov (2016), Hamid, Suleman, Ali Shah, and Imdad Akash (2017), Iyengar, Rao, Kosuri, and Vytla (2017) examined market efficiency, in its weak form, testing whether yields are predictable. Krsikapa-Rasajski and Rankov (2016) show that Servia's stock market, namely the two most important indices on the Belgrade stock exchange (BELEX 15 and BELEX LINE), are not efficient, in their weak form. The authors argue that this inefficiency is related to the underdevelopment of Servia's market, low trading volumes, lack of regulation, and transparency, which leads to a lack of investors. Hamid, Suleman, Ali Shah, and Imdad Akash (2017) analysed the financial markets of Pakistan, India, Sri Lanka, China, Korea, Hong Kong, Indonesia, Malaysia, Philippines, Singapore, Thailand, Taiwan, Japan, and Australia. The authors show that prices do not follow the random walk hypothesis. Iyengar, Rao, Kosuri, and Vytla (2017) investigated the efficiency of 11 prosperous markets reported by Goldman Sachs. The authors show that the stock markets PSI (Philippines), NSE 30 (Nigeria), BIST 100 (Turkey) and JKSE (Indonesia) are efficient, in their weak form. In addition, the results suggest integration into the stock markets of KOSPI (South Korea), EGX 30 (Egypt), HNXI (Vietnam), IPC (Mexico) and DSE (Bangladesh).

Narula (2018), Ali, Shahzad, Raza and Al-Yahyaee (2018), Rehman, Chhapra, Kashif, and Rehan (2018) examined the market efficiency, in its weak form, in the BRIC. Narula (2018) examined the efficiency of the BRICS markets in three periods: pre (January 1, 2006 to December 31, 2008), during (January 1, 2009 to December 31, 2010) and post (January 1, 2006) from 2010 to December 31, 2015). The general results of the study always prove the inefficiency of stock exchanges. The markets show signs of overreaction at various times, equilibrium is reached within a short period. The markets show trends of average reversal in all periods. Ali, Shahzad, Raza and Al-Yahyaee (2018) demonstrate that developed markets are relatively more efficient, followed by the BRICS stock markets. The authors show that almost all Islamic stock markets, except for Russia, Jordan and Pakistan, are more efficient than their conventional peers. Rehman, Chhapra, Kashif, and Rehan (2018) show that the stock indexes of Pakistan, India and Bangladesh are not efficient, in their weak form.

Da Silva, Guedes, Ferreira, Dionísio and Zebende (2019), Agustin (2019), Jain (2020), tested the random walk hypothesis, examining its efficiency. Da Silva, Guedes, Ferreira, Dionísio and Zebende (2019) analysed the main indices in the world: North America, South America, Asia and Europe. The authors show a perfect cross-correlation $\rho D C C A$ in the long run between the opening and closing prices; however, in the short run, there are differences between the different stock markets. Agustin (2019) examined the hypothesis of an efficient market, in its weak form, in the Indonesian market (ISSI); the author shows that ISSI is not efficient, in its weak form, during the study period. Jain (2020) examined efficiency, in its weak form, in the Indian market, showing signs of (in) efficiency in this stock market.

The authors Milos, Hatiegan, Milos, Barna, and Botoc (2020) verified the presence of long memories and long-term correlations, showing that the stock markets are not efficient, in their weak form, and have not yet reached a mature stage of development. Meanwhile, Karasiński (2020) examined efficiency, in its weak form, in European markets, and shows that global 
efficiency tended to improve after the 2008 global financial crisis. Lahmiri and Bekiros (2020) tested the market hypothesis efficient, in its weak form, on the Casablanca Stock Exchange (CSE), Dow Jones and S \& P500 stock markets. The authors show that prices are potentially predictable in the 3 markets and all industrial sectors.

In summary, this work aims to contribute to the provision of information to individual and institutional investors seeking benefits from diversification in the BRIC markets. Therefore, the context of this work is to examine the market efficiency, in its weak form, among these markets, in the period of the global pandemic (Covid-19).

\section{METHODOLOGY}

\section{DATA}

Data on the opening and closing prices of the stock markets in Brazil (BRAZIL IBOVESPA), China (Shanghai Stock Exchange), India (S\&P BSE SENSEX), Russia (MOEX Russia), were obtained from the Thomson Reuters platform. Prices are intraday (1 hour) and cover the period from May 2019 to May 2020, the same being in the local currency, to mitigate exchange rate distortions (see tables 1 and 2).

Table 1. The name of countries and their indices used in this paper

\begin{tabular}{|c|c|c|c|}
\hline Country & Index & Symbol & Currency \\
\hline Brazil & BRAZIL IBOVESPA & IBOV & BRL \\
\hline China & Shanghai Stock Exchange & SHCOMP & CNY \\
\hline India & S\&P BSE SENSEX & SENSEX & INR \\
\hline Russia & MOEX Russia & IMOEX & RUB \\
\hline
\end{tabular}

Source: Own elaboration.

Table 2. Sample intraday data (1 hour)

\begin{tabular}{|c|c|c|c|c|}
\hline Country & Start & End & Hours/Day & $\mathrm{N}$ \\
\hline Brazil & $15 / 05 / 201918: 00$ & $15 / 05 / 202018: 00$ & 8 & 1990 \\
\hline China & $15 / 05 / 201902: 00$ & $14 / 05 / 202007: 00$ & 5 & 1220 \\
\hline India & $16 / 05 / 201904: 30$ & $15 / 05 / 202010: 30$ & 7 & 1717 \\
\hline Russia & $15 / 05 / 201908: 00$ & $15 / 05 / 201916: 00$ & 9 & 2268 \\
\hline
\end{tabular}

Source: Own elaboration.

\section{METHODOLOGY}

The development of the research took place over several stages. Although Hurst's exponent is not used directly, a methodology that indirectly proposes the same information will be applied: the Detrended Fluctuation Analysis (DFA). DFA is an analysis method that examines time dependency on non-stationary data series. This technique, assuming that the time series are non-stationary, avoids spurious results when the analysis focuses on the relationships of the data series in the long run. This methodology was developed by Peng et al. (1994), having its origin in the study of DNA behaviour. This method was later used to examine the behaviour of financial series. The DFA has the following interpretation: $0<\alpha<0,5$ : series antipersistent; $\alpha=0,5$ series features random walk; $0,5<\alpha<1$ persistent series. 
The function of this technique is to examine the relationship between the values $x_{k}$ e $x_{k+t}$ at different moments (Ferreira, Dionísio, Guedes, and Zebende, 2018).

The Zebende (2011) non-trend cross-correlation coefficient is a method for quantifying the level of cross-correlation between two non-stationary time series. The coefficient is based on the DFA (Peng et al., 1994) and DCCA (Podobnik and Stanley, 2008) methods.

Thus, for a better understanding of the $\rho D C C A$, we will present your algorithm in five steps, namely:

Step 1: Considering two time series, $\mathrm{x}_{\mathrm{t}} \& \mathrm{y}_{\mathrm{t}}$, with $t=1,2,3, \ldots, N$ ( $N$ is the size of the time series). Then these time series are integrated, obtaining two new series

$$
\mathrm{xx}_{\mathrm{k}}=\sum_{\mathrm{t}=1}^{\mathrm{k}} \mathrm{x}_{\mathrm{t}} \text { e } \mathrm{yy}_{\mathrm{k}}=\sum_{\mathrm{t}=1}^{\mathrm{k}} \mathrm{y}_{\mathrm{t}}
$$

Stage 2: The two integrated series were divided, $\mathrm{xx}_{\mathrm{k}} \& \mathrm{yy}_{\mathrm{k}}$ with $(N-s)$ overlapping boxes of equal length $\mathrm{s}$, with

$$
4 \leq s \leq \frac{N}{4}
$$

Step 3: The local trend of each box is calculated by adjusting the least-squares of each series, $\mathrm{xP}_{\mathrm{i}}(\mathrm{k}) \& \mathrm{y} \mathrm{P}_{\mathrm{i}}(\mathrm{k})$. Then, we calculate the covariance of the residues in each box by:

$$
f_{x y}^{2}(s, i)=\frac{1}{(s+1)} \sum_{k=1}^{i+s}\left(x x_{k}-x P_{i}(k)\left(y y_{k}-y P_{i}(k)\right)\right)
$$

Step 4: The averages over all N-s, overlapping boxes are calculated to obtain a new covariance function:

$$
F_{x y}^{2}(s)=\frac{1}{(N-s)} \sum_{i=1}^{N-s} f_{x y}^{2}(s, i)
$$

Step 5: Finally, the cross-correlation coefficient is calculated $\rho$ DCCA by:

$$
\rho D C C A(s)=\frac{F_{x y}^{2}(s)}{F_{x x}(s) F_{y y}(s)}
$$

As we can see, the cross-correlation coefficient depends on the length of the box s (time scale). One of the advantages of this cross-correlation coefficient is centred on the possibility of measuring the correlations between two non-stationary time series at different time scales. The cross-correlation coefficient $\rho D C C A$ varies within the range $-1 \leq \rho \mathrm{DCCA} \leq 1$ logically 1 means perfect cross-correlation, -1 means perfect anti-cross-correlation and 0 means that there is no correlation (Zebende, 2011).

\section{RESULTS}

Figure 1 shows the evolution of the BRIC markets, in levels, from May 2019 to May 2020, with intraday data (1 hour), which is a period of considerable complexity, due to understanding the global pandemic (COVID -19). Yields reveal the marked volatility in January, February and March 2020. 
Figure 1. Evolution, in levels, of the opening, maximum, minimum and closing prices of the BRIC financial markets, in the Complete period
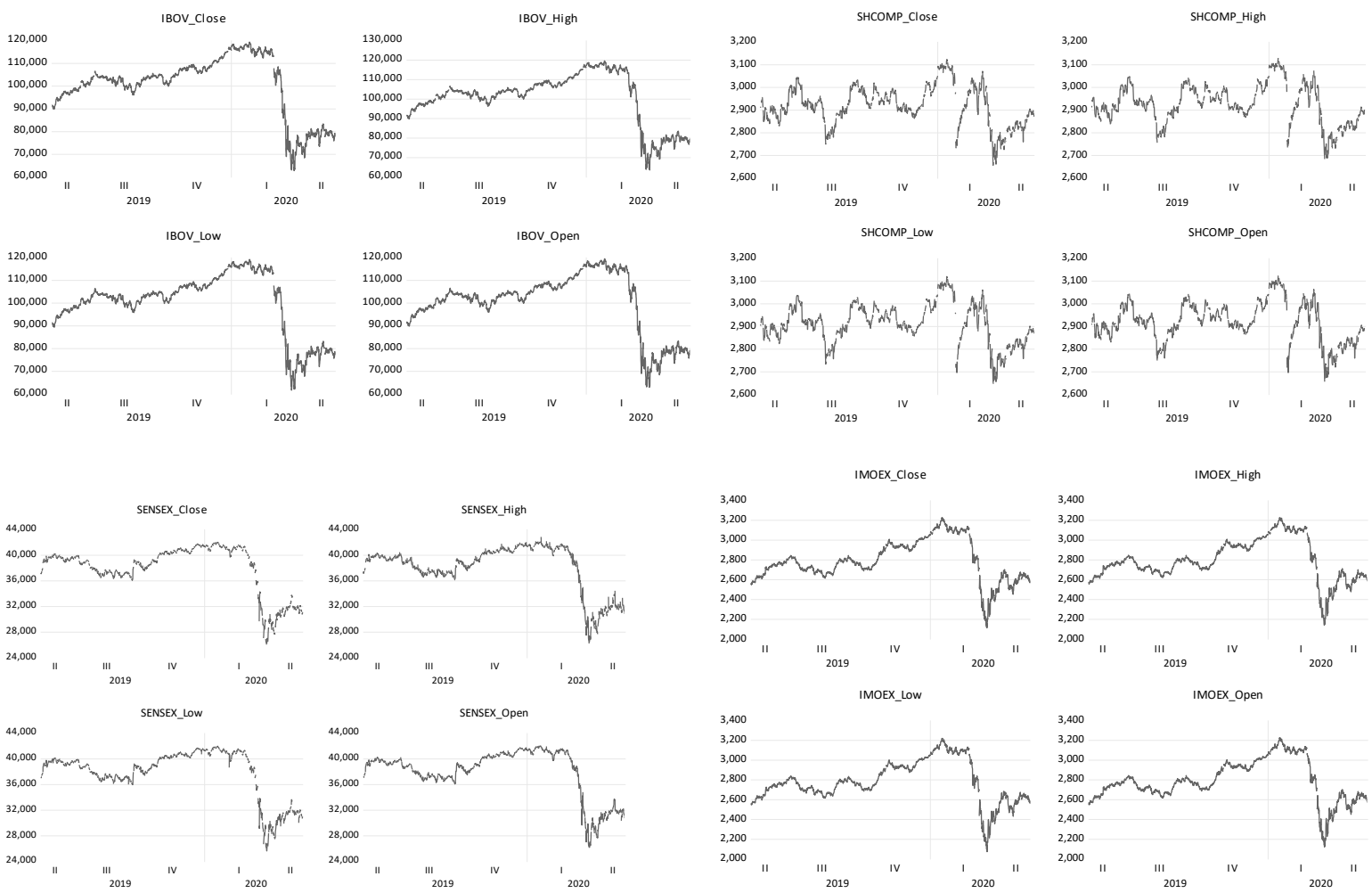

Source: Own elaboration.

Table 3 shows the main descriptive statistics on the profitability of the BRIC financial markets. The analysis of descriptive statistics allows us to verify that profitability has negative daily averages, except for the Russian market (IMOEX). In addition, the Brazilian market has the largest standard deviation, asymmetries are negative in the 4 markets. Short-circuits are above 3 , which shows signs of deviation from the hypothesis of normality, with a greater incidence in India (SENSEX). Additionally, the coefficients of asymmetry and kurtosis are statistically different from those of a normal distribution.

Table 3. Descriptive statistics on returns, of the BRIC financial markets, in the Complete period

\begin{tabular}{|c|c|c|c|c|c|c|}
\hline Data & Mean & Standard Deviation & Skewness & Kurtosis & Minimum & Maximum \\
\hline IBOV & $-3,5 \mathrm{E}-05$ & 0,004012169 & $-3,01101$ & 59,10114 & $-0,05812$ & 0,0352118 \\
\hline SHCOMP & $-4,9 \mathrm{E}-06$ & 0,002166613 & $-3,12864$ & 45,45041 & $-0,03272$ & 0,0092525 \\
\hline SENSEX & $-4,5 \mathrm{E}-05$ & 0,00311989 & $-3,43219$ & 76,81591 & $-0,04565$ & 0,0379368 \\
\hline MOEX & $1,72 \mathrm{E}-06$ & 0,002248933 & $-1,68925$ & 45,74062 & $-0,03474$ & 0,0200892 \\
\hline
\end{tabular}

Source: Own elaboration.

In table 4 we can see the DFA exponents referring to the stock indexes of the BRIC markets. Period I comprise a time scale below 5 days (effective functioning of the exchange), while period II is contained in a time scale above 10 days (effective functioning of the exchange). Most stock indices show, in period I, an opening exponent similar to the closing price, except for China markets $(0.51-0.53)$. The indexes closest to 0.5 , in the period $\mathrm{I}$, are the markets of 
Brazil, China, India. The Russian market, on the other hand, shows signs of some antipersistence. In period II, the BRIC markets have significant long-term memories, except for the China stock index (0.51). Therefore, it can be inferred that the assumption of the market efficiency hypothesis is questionable since the forecast of the market movement can be improved if considering the lagged movements of the other markets, allowing the occurrence of arbitrage operations. These results are validated by the authors Liu, Manzoor, Wang, Zhang and Manzoor (2020), Şenol and Zeren (2020), Mzoughi et al. (2020) that show that the global pandemic (Covid-19) has an impact on the memory properties of financial markets.

Table 4. DFA exponent for index and return. The values of the linear adjustments for $\alpha$ DFA always had R2 > 0.99 .

\begin{tabular}{|c|c|c|c|c|c|c|}
\hline \multicolumn{2}{|c|}{} & \multicolumn{2}{c|}{ Open } & \multicolumn{2}{c|}{ Close } & \\
\hline Country & Symbol & Period I & Period II & Period I & Period II & Hours/Day \\
\hline Brazil & IBOV & 0.52 & 0.64 & 0.52 & 0.64 & 8 \\
\hline China & SHCOMP & 0.51 & 0.51 & 0.53 & 0.52 & 5 \\
\hline India & SENSEX & 0.50 & 0.64 & 0.50 & 0.64 & 7 \\
\hline Russia & IMOEX & 0.44 & 0.73 & 0.44 & 0.73 & 9 \\
\hline
\end{tabular}

Source: Own elaboration.

Table 5 presents the results for $\rho x, y$ between stock exchange indices for opening and closing prices. Our results show that in most markets and, for time scales $\mathrm{n}>=10$ days, we have a value of $r h o D C C A$ close to 1 (strong correlation) showing a trend towards a perfect crosscorrelation of $\rho D C C A$, that is, a tendency towards convergence, which means fewer memory signals, being evident in the markets of China (SHCOMP) and Russia (IMOEX). However, our results show, for time scales $\mathrm{n}<=5$ days, the existence of low cross-correlations $\rho D C C A$, that is, we have a value of rhoDCCA leaving 0 (weak correlation), between the opening and closing returns on the stock market indexes of Brazil (IBOV) and India (SENSEX). These findings show signs of (in) efficiency, that is, some periods can be used by investors to obtain anomalous returns without incurring additional risk.

Table 5. $\rho x, y$ as a function of time scale $n$ for $D C C A$ cross-correlation between Open and Close stock market index
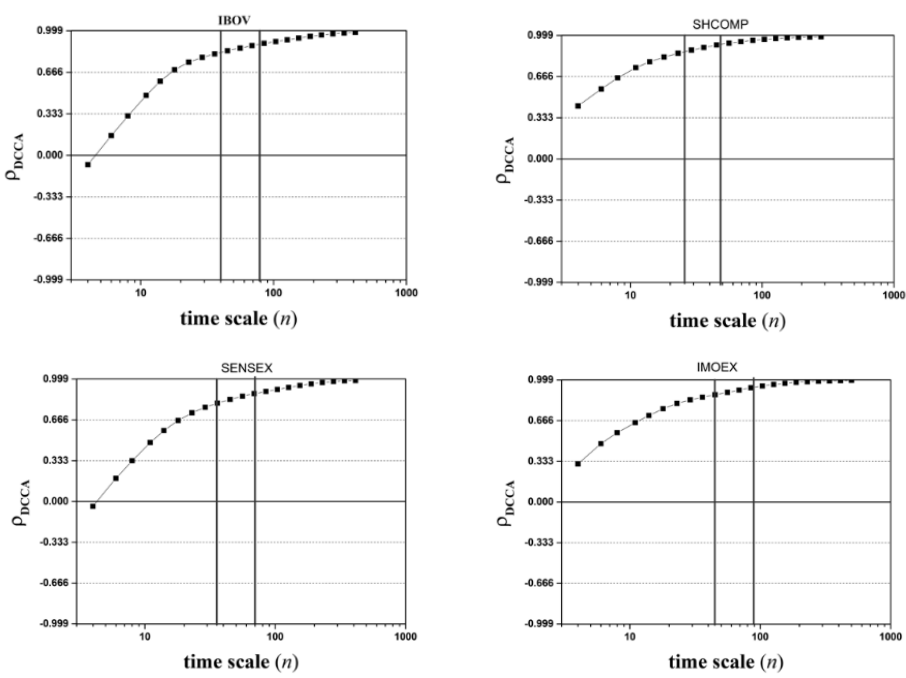

Source: Own elaboration. 


\section{CONCLUSION}

The general conclusion to be retained and sustained by the results obtained, through tests carried out with econophysical models, demonstrate that the global pandemic has a significant impact on the adjustment of the analysed financial markets. The results indicate that the BRIC markets have significant persistence (over 10 days), which may jeopardize market efficiency, in its weak form. On the other hand, the low initial correlation in certain stock indexes may create some arbitrage opportunities. However, our study did not analyse anomalous returns in these financial markets. These conclusions also open space for market regulators to take steps to ensure better informational information between the BRIC markets and the international financial markets. In conclusion, we believe that investors should diversify their portfolios, and invest in less risky markets such as the market for some commodities (precious metals), in order to mitigate risk and improve the efficiency of their portfolios.

\section{REFERENCES}

Agustin, I. N. (2019). Testing Weak Form of Stock Market Efficiency at The Indonesia Sharia Stock Index. Muqtasid: Jurnal Ekonomi Dan Perbankan Syariah. https://doi.org/10.18326/muqtasid.v10i1.17-29

Ali, S., Shahzad, S. J. H., Raza, N., \& Al-Yahyaee, K. H. (2018). Stock market efficiency: A comparative analysis of Islamic and conventional stock markets. Physica A: Statistical Mechanics and Its Applications. https://doi.org/10.1016/j.physa.2018.02.169

da Silva, L. S. A., Guedes, E. F., Ferreira, P., Dionísio, A., \& Zebende, G. F. (2019). px,y between open-close stock markets. Physica A: Statistical Mechanics and Its Applications. https://doi.org/10.1016/j.physa.2019.122152

El Khamlichi, A., Sarkar, K., Arouri, M., \& Teulon, F. (2014). Are Islamic equity indices more efficient than their conventional counterparts? Evidence from major global index families. Journal of Applied Business Research. https://doi.org/10.19030/jabr.v30i4.8660

Fama, E. F., \& French, K. R. (1988). Dividend yields and expected stock returns. Journal of Financial Economics, 22(1), 3-25. https://doi.org/10.1016/0304-405X(88)90020-7

Ferreira, P., Dionísio, A., Guedes, E. F., \& Zebende, G. F. (2018). A sliding windows approach to analyse the evolution of bank shares in the European Union. Physica A: Statistical Mechanics and Its Applications, 490, 1355-1367. https://doi.org/10.1016/j.physa.2017.08.095

Hamid, K., Suleman, M. T., Ali Shah, S. Z., \& Imdad Akash, R. S. (2017). Testing the Weak Form of Efficient Market Hypothesis: Empirical Evidence from Asia-Pacific Markets. SSRN Electronic Journal. https://doi.org/10.2139/ssrn.2912908

Iyengar, P., Rao, K. T. V., Kosuri, L., \& Vytla, A. (2017). Testing weak form of market efficiency in next 11 emerging markets. International Journal of Economic Research.

Jain, E. (2020). Empirically testing weak form efficiency of Indian stock market: Pre and post demonetization. International Journal of Scientific and Technology Research.

Jimmy Whitworth. (2020). COVID-19: a fast evolving pandemic | Transactions of The Royal Society of Tropical Medicine and Hygiene | Oxford Academic. Transactions of The Royal Society of Tropical Medicine and Hygiene.

Karasiński, J. (2020). The Changing Efficiency of the European Stock Markets. Annales Universitatis Mariae Curie-Skłodowska, Sectio $H-$ Oeconomia. https://doi.org/10.17951/h.2020.54.1.41-51

Krsikapa-Rasajski, J., \& Rankov, S. (2016). Testing weak form efficiency on the capital markets in Serbia. Megatrend Revija. https://doi.org/10.5937/megrev1601265k

Lahmiri, S., \& Bekiros, S. (2020). Nonlinear analysis of Casablanca Stock Exchange, Dow 
Jones and S\&P500 industrial sectors with a comparison. Physica A: Statistical Mechanics and Its Applications. https://doi.org/10.1016/j.physa.2019.122923

Liu, H., Manzoor, A., Wang, C., Zhang, L., \& Manzoor, Z. (2020). The COVID-19 outbreak and affected countries stock markets response. International Journal of Environmental Research and Public Health. https://doi.org/10.3390/ijerph17082800

Ma, C., Rogers, J. H., \& Zhou, S. (2020). Global Economic and Financial Effects of 21st Century Pandemics and Epidemics. SSRN Electronic Journal. https://doi.org/10.2139/ssrn.3565646

Mehla, S., \& Goyal, S. K. (2013). Empirical Evidence on Weak Form of Efficiency in Indian Stock Market. Asia-Pacific Journal of Management Research and Innovation. https://doi.org/10.1177/2319510x1200800107

Milos, L. R., Hatiegan, C., Milos, M. C., Barna, F. M., \& Botoc, C. (2020). Multifractal detrended fluctuation analysis (MF-DFA) of stock market indexes. Empirical evidence from seven central and Eastern European markets. Sustainability (Switzerland). https://doi.org/10.3390/su12020535

Mobarek, A., \& Fiorante, A. (2014). The prospects of BRIC countries: Testing weak-form market efficiency. Research in International Business and Finance, 30(1), 217-232. https://doi.org/10.1016/j.ribaf.2013.06.004

Mzoughi, H., Urom, C., Uddin, G. S., \& GUESMI, K. (2020). The Effects of COVID-19 Pandemic on Oil Prices, CO2 Emissions and the Stock Market: Evidence from a VAR Model. SSRN Electronic Journal. https://doi.org/10.2139/ssrn.3587906

Narula, I. (2018). Stock price randomness of BRICS nations. International Journal of Public Sector Performance Management. https://doi.org/10.1504/IJPSPM.2018.090744

Peng, C. K., Buldyrev, S. V., Havlin, S., Simons, M., Stanley, H. E., \& Goldberger, A. L. (1994). Mosaic organization of DNA nucleotides. Physical Review E, 49(2), 1685-1689. https://doi.org/10.1103/PhysRevE.49.1685

Podobnik, B., \& Stanley, H. E. (2008). Detrended cross-correlation analysis: A new method for analyzing two nonstationary time series. Physical Review Letters, 100(8). https://doi.org/10.1103/PhysRevLett.100.084102

Rehman, S., Chhapra, I. U., Kashif, M., \& Rehan, R. (2018). Are Stock Prices a Random Walk? An Empirical Evidence of Asian Stock Markets. ETIKONOMI. https://doi.org/10.15408/etk.v17i2.7102

Saadat, S., Rawtani, D., \& Hussain, C. M. (2020). Environmental perspective of COVID-19. Science of the Total Environment. https://doi.org/10.1016/j.scitotenv.2020.138870

Şenol, Z., \& Zeren, F. (2020). Coronavirus (COVID-19) and Stock Markets: The Effects of the Pandemic on the Global Economy. Avrasya Sosyal ve Ekonomi Araştırmaları Dergisi.

Zebende, G. F. (2011). DCCA cross-correlation coefficient: Quantifying level of crosscorrelation. Physica A: Statistical Mechanics and Its Applications, 390(4), 614-618. https://doi.org/10.1016/j.physa.2010.10.022 